\title{
A tricky fetal case of isolated transposition of great arteries without the I-shaped sign
}

\author{
Yukiko Kawazu $^{1}$, Kayoko Takahashi ${ }^{1}$, Tomoko Tsujie ${ }^{1}$, and Kosuke Chayama ${ }^{1}$ \\ ${ }^{1}$ Toyonaka Municipal Hospital
}

May 16, 2020

\begin{abstract}
Isolated transposition of great arteries (TGA) is a congenital heart disease that presents with severe cyanosis after birth and a fetal diagnosis is crucial for preserving life. The I-shaped sign (I-sign) is useful as a fetal screening method for TGA. We herein present a tricky fetal case of isolated TGA in the side-by-side arterial position without the I-sign. Severe cyanosis immediately after birth necessitated urgent interventions. Death was prevented because of the fetal diagnosis. In the fetal diagnosis of isolated TGA, it is important to not only detect the I-sign, but also conventionally examine the ventricular outflow tract.
\end{abstract}

\section{Hosted file}

2020.5.16 trickyTGA Kawazu.doc available at https://authorea.com/users/322620/articles/ 451574-a-tricky-fetal-case-of-isolated-transposition-of-great-arteries-without-the-ishaped-sign

Fig.1

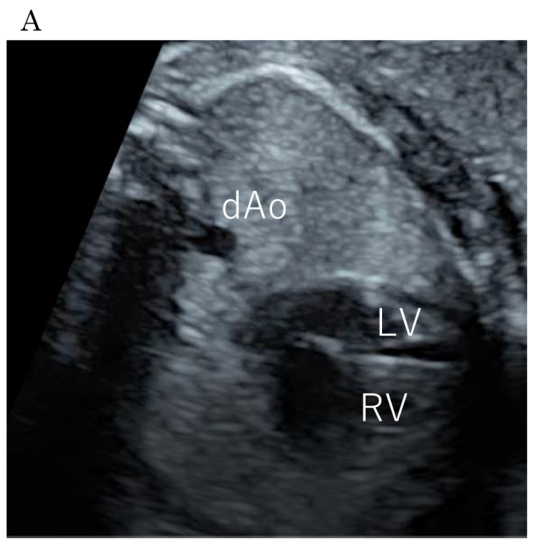

B

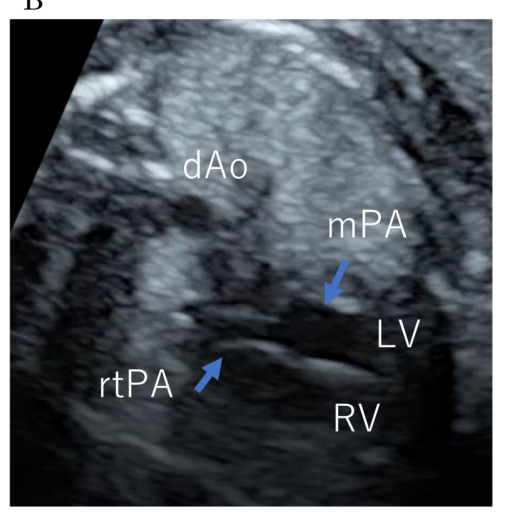

